\title{
A Capstone Course in Speech-Language Pathology
}

Linda C. Murdock

University of Montevallo, murdocklc@montevallo.edu

Carson M. York

University of Montevallo, murdocklc@montevallo.edu

DOI: https://doi.org/10.30707/TLCSD5.1.1624982519.5176

Follow this and additional works at: https://ir.library.illinoisstate.edu/tlcsd

Part of the Speech and Hearing Science Commons, and the Speech Pathology and Audiology Commons

\section{Recommended Citation}

Murdock, Linda C. and York, Carson M. (2021) "A Capstone Course in Speech-Language Pathology," Teaching and Learning in Communication Sciences \& Disorders: Vol. 5: Iss. 1, Article 3.

DOI: https://doi.org/10.30707/TLCSD5.1.1624982519.5176

Available at: https://ir.library.illinoisstate.edu/tlcsd/vol5/iss1/3

This Reflection on SoTL is brought to you for free and open access by ISU ReD: Research and eData. It has been accepted for inclusion in Teaching and Learning in Communication Sciences \& Disorders by an authorized editor of ISU ReD: Research and eData. For more information, please contact ISUReD@ilstu.edu. 


\title{
A Capstone Course in Speech-Language Pathology
}

\author{
Abstract \\ Capstone courses are considered a high impact practice with the potential to positively affect student \\ learning. This article describes the design and implementation of a capstone in speech-language \\ pathology designed to round out the undergraduate experience by shifting the learning focus away from \\ disorder characteristics and onto individuals living with disabilities. The course is designed to teach \\ students compassion, self-evaluation, and strategies for personal growth.

\section{Keywords} \\ Capstone, undergraduate, high impact practice
}


With colleges more focused on retention, faculty are being asked to evaluate our programs and our teaching methods to ensure that we are meeting our learning outcomes and giving students every chance to succeed. Part of this focus is on incorporating more high impact practices (HIP), such as first year experiences, learning communities, and capstone courses (Brownell \& Swaner, 2010). HIPs, including capstone experiences, have been shown to have positive effects on student learning (Kilgo et al., 2015). Capstone experiences take many forms, including portfolios, theses, senior examinations, projects, and internships. Regardless of the form, a capstone should provide a culminating experience that allows students to integrate curricular knowledge in a manner that helps to prepare them for the next step, either graduate school or the working world. In a recent survey regarding faculty perceptions of HIPs, faculty rated the capstone experience as the most impactful of these practices, ahead of items such as first-year experience and undergraduate research (Paulson, 2012). Overall, 79\% of faculty respondents indicated a belief that capstone experiences improve the learning of all students and $74 \%$ indicated these practices to be particularly impactful to underserved students.

Capstone experiences can help students understand "how they have changed and developed, and what they have to offer employers and the larger society" (Wawrzynski \& Baldwin, 2014, p. 58). Essentially, the course should help students to see the big picture of how to use the information they have learned in a real-world context. In communication sciences and disorders (CSD), this means thinking about how to use the knowledge they have acquired to serve our clients. Very little has been written specifically about capstones in CSD. No formal recommendations have been published regarding the content of these courses for CSD, and programs are utilizing varying approaches, including team-based learning in evidence-based practice (Wallace, 2015) and hypothetical client case review (Keegan et al., 2017). In a recent national survey, $44 \%$ of the 61 responding CSD programs reported offering an undergraduate capstone experience (Magimairaj \& McDaniel, 2017). Respondents were asked to rank their most highly valued learning objectives for senior seminar courses. These included improving oral and written communication skills, understanding models of learning and relearning across the lifespan, integrating discipline-specific knowledge, and understanding the client and family perspective on communication impairment. Although no one course could reasonably address all of these objectives, it may be possible to use these for guidance as programs design and evaluate our capstone experiences. The purpose of this article is to describe the evolution of one capstone course in CSD that targets multiple student learning outcomes in novel way.

A few years ago, my university began requiring each undergraduate program to have some form of culminating experience: either a project, internship, or capstone course. As a faculty, we struggled to decide what that experience should be. Different options were discussed, and a few were attempted with varying degrees of success. One attempt involved a course focused on a deeper exploration of the theoretical underpinnings of our clinical practice. This attempt was not met with high levels of student enthusiasm. Other ideas involved guided clinical observations, junior clinician partnerships with graduate students, and grand rounds types of discussions. Eventually, we decided on a capstone course that was less focused on content knowledge and more on rounding out our students as individuals within a field. The overarching construct for the course was consistent with some of the current thinking in higher education that curriculum should "evoke in our students a higher order of personhood, one that becomes whole, or integral, in some meaningful sense by virtue of the higher education experience" (Long, 2012, p. 127). 
In planning the capstone course, it was important to consider the idea of what a well-rounded graduate of the program should look like. Most students would be going on to graduate school in speech-language pathology or audiology, but others would be starting careers, working as speechlanguage pathology assistants, or attending other types of graduate programs in areas such as special education, counseling, or social work. What skills would these students need in order to be successful in the workplace, and how could a course ease the transition from student to professional? The overall course plan emerged out of three constructs: developing an understanding of clients as people rather than disorders, developing a stronger understanding of the strengths and weaknesses that each of us bring to the table, and beginning to see one's self as a professional in a career rather than a student in a major. Over the years, a fourth construct, development of resilience, was added based on a theme that emerged throughout the other readings and class discussions.

The overall structure of the course is built on reflecting and discussing. There are no tests or quizzes. Students are graded on journal reflections of our readings and participation in discussions. It is important to note that the course is offered in the spring term of the senior year in a face-toface format with a typical enrollment of 15-25 students. What follows is a description of each construct of the course and an explanation of the methods and materials used to target each component. This is followed by a reflection on the class by a recent graduate. The purpose of this manuscript is to provide a model of a capstone course in CSD that might serve as an example for other programs.

\section{Clients as People}

After reflecting on the undergraduate curriculum, it seemed that students had spent a significant amount time learning about anatomy, development, and disorders without having been tasked with considering the individuals and families living with the disorders. The current standards for accreditation from the Council on Academic Accreditation in Audiology and Speech-Language Pathology (CAA) highlight the importance of family-centered care and developing concern and respect for the individuals served (CAA, 2019). Bruce, DiVenere, and Bergeron (1998) stated that "academic programs have an ethical obligation to create training experiences that instill a philosophy of family-centered care" (p. 92). These types of training experiences have resulted in improved skills and attitudes for CSD students (e.g., Bruce et al., 1998; Kim \& Garcia, 2019; Sylvan, 2019).

The book for this portion of the course is Counseling in Communicative Disorders: A Wellness Perspective (Holland \& Nelson, 2020). This text asks the students to consider what it would be like to have your child diagnosed with a life-long disorder like Autism or to have your spouse experience a stroke and lose the ability to communicate and take care of himself. Students read the chapters and write 1-2 pages in a journal reflecting on the content. The book teaches listening and responding techniques which are then practiced by the students. For example, during a role-play, one student acts as the client, making an emotional comment or asking a sensitive question, while their partner practices active listening techniques. Then both collaborate to provide an example of each response type: active constructive, passive constructive, active destructive, and passive destructive (Holland \& Nelson, 2020). Through this content, students have the opportunity to learn 
empathy, patience, and nonjudgment. We want them to begin to consider, possibly for the first time, how they will communicate with future clients and the power that their words will have. This material is assessed through journal reflections, which provide the opportunity to evaluate the depth of the connections that they are making and also the chance to reinforce basic writing skills. This portion of the course provides the opportunity for the instructor to work in some mini lessons on semicolons and run-on sentences. Journal prompts in this section of the course include items such as:

- What skills do you bring to the table?

- What will you need to temper or change about yourself to be a successful counselor?

- Please reflect on your own patterns of listening and responding. Do you listen with the willingness to have your mind changed? What is your responding pattern? What are the opportunities for growth in these areas?

The journals are graded with a high level of detail, especially in the beginning. Students receive instructive feedback on punctuation, sentence structure, and grammar. The rubric is descriptive in nature. A response that earns the full 10 points is described as follows:

Student's writing clearly indicates the student has read, absorbed, and linked the material to their previous knowledge, thoughts and/or beliefs. Answers are mature, self-reflective, poignant, and reflect interest and maximum effort toward the assignment. Grammar, spelling, sentence structure, word choice, and editing are strong. No more than one typo or small error.

Students complete more than 10 journal entries for the course, providing the instructor with a unique opportunity to hold students accountable for improving their skills. Often students will start out earning a 6/10 and find out that they need to reflect more deeply and fine tune grammar and proofreading skills.

\section{Understanding Ourselves}

As we interact in teams, it is important to understand how our personality characteristics and communication styles impact the way that we provide services (Handelsman, 2016). Moreover, generational differences can impact how a student responds to clinical teaching (McCready, 2011; Plexico et al., 2017). This portion of the course focuses on three topics: identifying our character traits, generational understanding, and conflict resolution. This material is introduced through one of the most appreciated activities in the course, the completion of the VIA Survey of Character Strengths (Peterson \& Seligman, 2005) provided by the Positive Psychology Center at the University of Pennsylvania. This is a somewhat lengthy assessment, but it ends up being quite revelatory. Students learn their five signature strengths as well as traits they possess to a lesser degree. Some of the traits can be surprising: capacity to love and be loved; humility; enthusiasm, zest, and energy; love of learning; sense of humor, and appreciation of art and beauty in the world. Many students have never considered these traits to be valuable and useful to others. Students are challenged to use the strengths in new and different ways, and to reflect upon ways they can call upon these qualities when working with clients and families. This assignment helps students begin to realize that clinicians develop their own styles that are influenced by innate talents and personality traits. Students often report improved self-confidence upon learning that academic ability is only one of a host of important character traits for this profession. 
After examining traits at an individual level, the class moves on to studying generational characteristics. When the course first began, most students were members of the millennial generation, but now most of the students hail from generation $\mathrm{Z}$. The current text for this portion of the course is Gen Z @ Work: How the Next Generation is Transforming the Workplace (Stillman $\&$ Stillman, 2017). Through this material, students learn about the values and expectations of traditionalists, baby-boomers, Gen X'ers, and Gen Z'ers. They learn how other generations perceive issues like cell phone use on the job or flexible work hours. These readings allow students to think about the impressions they want to create and how to handle generational conflicts. Often students report they were unaware of these types of generational biases and expectations. Journals and discussions center on how this knowledge can be utilized to avoid miscommunications and forge better relationships with employers, clients, and clients' family members. The instructor provides a prompt for the written response (e.g., Look at the 7 key attributes of gen $\mathrm{Z}$ and choose a few to talk about. Do you agree with them? How might these attributes help or hinder you in the workplace?). Students are also given a list of ideas to prepare for the discussion. The discussions are instructor-led and done in a whole-class format, although with a large course, it might be necessary to break into groups. When possible, the instructor grades the journals before class and references back to key points or ideas expressed in the journals if the discussion lags.

Once the idea of conflict in the workplace is introduced, it seems important to spend some time discussing conflict resolution techniques. This component of the course typically leads to lively discussion and enhanced self-awareness. It is often surprising to students that conflict is not inherently bad and not all conflict should be avoided. Distinct conflict styles are taught: competing, accommodating, avoiding, collaborating, and compromising (McShane \& Von Glinow, 2008). There is a place and time when each style can be effectively employed. Students learn that avoiding conflict is not always the best option, but neither is compromise. Students take a short quiz to help identify their tendencies toward a particular style and write a journal entry describing how they could begin to use other conflict styles effectively. I would suggest collaborating with colleagues in the business department; my colleagues helped identify materials and textbook chapters on conflict resolution, such as McShane \& Von Glinow (2008) as referenced above.

\section{Transition from Student to Professional}

Whether transitioning to the workplace or to graduate school, students are moving into a new phase of life where expectations are higher and independence is expected. Part of the mission of our department is to prepare students to become clinical leaders. As a faculty, we want to help students make the transition to a more active style of learning and to begin to see themselves as clinicians rather than students. One way to facilitate this shift in thinking is to ask students to lead conversations about the issues faced by working professionals in the field. For this portion of the course, students work in teams to create reading lists from publications like the ASHA Leader. The team creates a question set and facilitates a class discussion on their topic. Class members complete these readings and are graded on their contributions to the discussions. Topics include issues like productivity requirements, caseload caps in school systems, advocacy for clients and the profession, funding caps, and diversity within the profession. At the end of this unit, hopefully students begin to feel more a part of the profession and begin to imagine themselves dealing with these issues in the workplace. 
In terms of grading, the class is divided into two teams, and the instructor only grades half the students on a given day to prevent everyone from talking over one another in a mad dash for participation points. Students know which team is being graded and those not being graded are asked to yield the floor if the discussion becomes crowded. The grading rubric contains indicators such as actively supports, engages, and listens to peers, and comments advance the level and depth of the dialogue.

\section{Resilience}

One criticism of millennials and, to a lesser extent, generation $\mathrm{Z}$ is a lack of resilience (Rosenbaum, 2017). Resilience can be described as an ability to recover quickly from adversity. A recent national study of graduate students in CSD found that $96 \%$ reported moderate and high levels of stress, with students suggesting faculty should provide specific resources and classes to address the issue (Lieberman et al., 2018). Graduate students in CSD have reported the need for increased coping strategies due feelings of being overwhelmed during their academic programs (Rapillard et al., 2019). Resilience has been shown to moderate the effect of emotional exhaustion on psychological heath of students (Garcia-Izquierdo et al., 2018). The construct of resilience was one that came up repeatedly throughout the course and it began to be clear that students did not have a strong understanding of the true importance of resilience and how to go about developing it. In the counseling book, resilience is highlighted in stories of clients thriving despite adversity and overcoming challenges. A portrait emerges of individuals choosing to live their lives to the fullest degree possible despite circumstances not working out as imagined or planned. Resilience is the defining factor in this.

Because of the prominence of this theme across the course material, an additional book is now required, The Resilience Break-Through: 27 Tools for Turning Adversity into Action (Moore, 2014). The book provides an assessment designed to identify the types of resilience each student possesses: street, resource, relational, or rock-bottom. I ask students to read chapters about two types of resilience, one they possess and one they do not. Students then participate in two small group discussions, once as a teacher and once as a learner. The teachers share their experiences with a given type of resilience and help the learners think through ways they could improve skills in that area. The overarching theme is the idea that resilience can be developed largely by reframing our thought processes and choosing to hold ourselves accountable. This content teaches strategies such a developing a growth mindset and "flipping the switch" (Moore, 2014, p. 25) so that we see opportunities rather than obstacles. On course evaluations, many students indicate this is their favorite component of the course and report success capitalizing on the four areas of resilience in both their personal and professional lives.

\section{Student Perspective}

An important aspect of reflecting on the success of the course is to consider a student perspective. The following is from a first-year graduate student who was asked to write a reflection on her experience in the capstone course the preceding year: 
If the truth be told, I would be lying if I said I wasn't at least slightly relieved to hear that one of my last classes as a senior in college was going to be graded on journal entries. Zero tests? Count me in. It was not until I sat at my kitchen table, digging deeper and deeper into self-reflection for that first entry that it hit me- the concreteness of a typical test sounded like a walk in the park compared to this. Anatomy of the larynx? I can memorize it. The International Phonetic Alphabet? Got that covered too. Reflecting on my 23 years of life to determine my conflict resolution style? Notecards won't help me for this one.

I vividly remember the first day of class when the instructor told us that there would be days that felt like a therapy session, and it wasn't until I saw a pattern of tears shed, and comradery established that her words began to reverberate in my mind. She was rightsenior seminar had in fact become therapeutic for me. I watched my peers, who normally kept to themselves in class, open up about intimate details of their lives and work towards achieving the idea of vulnerability we had previously discussed in class. I began to feel encouraged by my classmates' transparency, and proud when I began to embrace my own. As clinicians, we learn the importance of meeting people where they are at in order to take them forward. This class served as an excellent reminder that before I can take anyone else forward, I must first meet myself.

My first semester of graduate school has been that of trial and error. The expectations have increased dramatically, as well as the responsibilities to meet them. Since embarking on this journey, I have found myself time and time again reflecting back to concepts I learned from senior seminar. The weeks I'm certain I've reached a personal record for stress? I could use a refresher on that rock bottom resilience. The days when calling the shots in my own clinical practice seems nothing short of terrifying? Time to take a step back and remind myself of the power of vulnerability. Sure, making an "A" on that test you have studied so hard for feels great. Passing the class you thought you'd never get through- that feels good too. But gathering the courage to not only dive into the not-so-perfect details of your life, but embrace your newfound vulnerability and share with your peers? That is a rewarding feeling all in its own.

\section{Conclusion}

Although research into effective capstone courses in CSD is limited, findings from a previously discussed study (Magimairaj \& McDaniel, 2017) suggested several student learning objectives for capstone courses. The model described here aligns well with these objectives. Oral language skills are targeted as teams work together to lead a discussion of the issues facing our field and as their peers respond and participate in this discussion. Written communication skills are targeted through extensive graded journaling, providing students the opportunity to receive continuous and specific feedback on their writing. The counseling content asks students to consider the client perspective and the challenges of living with a communication disorder. Additionally, students learn about their personal and generational characteristics and how they can apply those talents and accommodate their own shortcomings as they provide services to clients.

Moving forward with the course, it will be important to stay on top of generational trends. Failing to move quickly from a book on the millennial generation to the generation $\mathrm{Z}$ content was a mistake 
readily pointed out on student course evaluations. Additionally, it took a few semesters to understand the need to add in several mini-lessons on grammar and punctuation. This was a bitter pill to swallow at the senior level, but time spent correcting individual papers has decreased due to increased whole-group instruction. One challenge I continue to face is having to safeguard the course against the encroaching need to gather senior-level student learning outcome data for the program and the university.

In conclusion, in the absence of undergraduate clinic, it can be difficult to identify a meaningful and manageable way to provide a summative overarching experience in CSD programs. The framework provided here is one example that focuses on self-exploration and improvement, the impending shift in mindset from student to professional, and learning to focus on the people we serve rather than disorders they possess.

\section{Disclosures}

Authors nave no financial or nonfinancial relationships related to this submission.

\section{References}

Brownell, J. E., \& Swaner, L. E. (2010). Five high-impact practices: Research on learning outcomes, completion, and quality. American Association of Colleges and Universities.

Bruce, M. C., DiVenere, N., \& Bergeron, C. (1998). Preparing students to understand and honor families as partners. American Journal of Speech-Language Pathology, 7(3), 85-94.

Council on Academic Accreditation in Audiology and Speech-Language Pathology. (2019). Standards for accreditation of graduate programs in audiology and speech-language pathology. $\quad$ https://caa.asha.org/wp-content/uploads/Accreditation-Standards-forGraduate-Programs.pdf

Garcia-Izquierdo, M., Rios-Risquez, M. I., Carillo-Garcia, C., \& Sabuco-Tebar, E. (2018).The moderating role of resilience in the relationship between academic burnout and the perception of psychological health in nursing students. Educational Psychology, 38(8), 1068-1079. https://doi .org/10.1080/01443410.2017.1383073

Handelsman, J. A. (2016). Enhancing cross-generational communication. ASHA Leader, 21(6), 67. https://doi.org/10.1044/leader.FTP.21062016.6

Holland, A. L., \& Nelson, R. L. (2020). Counseling in communicative disorders: A wellness perspective. Plural Publishing.

Keegan, L. C., Losardo, A., \& McCullough, K. (2017). Problem-based learning for undergrads. ASHA Leader, 22(5), 34-35. https://doi.org/10.1044/leader.AE.22052017.34

Kilgo, C. A., Ezell Sheets, J. K., \& Pascarella, E. T. (2015). The link between high-impact practices and student learning: Some longitudinal evidence. Higher Education, 69(4), 509-525. https://doi.org/10.1007/s10734-014-9788-z

Kim, E. S. \& Garcia, J. R. (2019). "That's so much more important than the grades": Learning client centered care through experiential learning at aphasia camp. Teaching and Learning in Communication Sciences and Disorders, 3(2), Article 3. https://doi.org/10.30707/TLCSD3.2Kim

Lieberman, R., Raisor-Becker, L., \& Sotto, C. (2018). Investigation of graduate student stress in speech language pathology. Teaching and Learning in Communication Sciences and Disorders, 2(2), Article 6. https://doi.org/10.30707/TLCSD2.2Lieberman 
Long, T. E. (2012). Evoking wholeness: To renew the ideal of the educated person. In D.W. Harward (Ed.), Transforming undergraduate education (pp. 125-140). Rowan \& Littlefield.

Magimairaj, B. M. \& McDaniel, K. (2017). A survey of undergraduate capstone course objectives in communication sciences and disorders. Journal of Allied Health, 46(4), e59-e65. https:///www.ingentaconnect.com/content/asahp/jah

McCready, V. M. (2011). Generational issues in supervision and administration. ASHA Leader, 16(5), 12-15. https://doi.org/10.1044/leader.FTR1.16052011.12

McShane, S. L. \& Von Glinow, M. A. (2008). Organizational Behavior (2nd ed.). McGraw-Hill.

Moore, C. (2014). The resilience breakthrough: 27 tools for turning adversity into action. Greenleaf Book Group Press.

Paulson (2012). Faculty Perceptions of General Education and the Use of High-Impact Practices. Peer Review, 14(3). https://www.aacu.org/publications-research/periodicals/facultyperceptions-general-education-and-use-high-impact

Peterson, C., \& Seligman, M. E. P. (2005). VIA Survey of character strengths. Values in Action Institute. $\quad$ https://ppc.sas.upenn.edu/resources/questionnaires-researchers/surveycharacter-strengths

Plexico, L. W., Plumb, A. M., \& Phillips, D. E. (2017). Speech-language pathology student anxiety, expectations, and needs during clinical practicum. Teaching and Learning in Communication Sciences and Disorders, 1(2), Article 2. https://doi.org/10.30707/TLCSD1.2Plexico

Rapillard, S., Plexico, L. W., \& Plumb, A. M. (2019). Influence of graduate speech language pathology student's learning style and coping strategies on training and development. Teaching and Learning in Communication Sciences and Disorders, 3(1), Article 2. https://doi.org/10.30707/TLCSD3.1Rapillard

Rosenbaum, P. (2017). Resilience in college students. Journal of College Student Psychotherapy, 31(2) 91-92. https://doi.org/:10.1080/87568225.2017.1297640

Stillman, D. \& Stillman, J. (2017) Gen Z @ work: How the next generation is transforming the workplace. Harper Collins.

Sylvan, L. (2019). How to teach concern: Inspiring speech-language pathology graduate students to develop empathy and advocacy with the power of personal stories. Teaching and Learning in Communication Sciences and Disorders, 3(2), Article 9. https://doi.org/ 10.30707/TLCSD3.2Sylvan

Wallace, S. E. (2015). Team-based learning in a capstone course in speech-language pathology. Communications Disorders Quarterly, 37(1), 44-52.

https://doi.org/: 10.1177/152574011558462

Wawrzynski, M. \& Baldwin, R. (2014). Promoting high-impact student learning: Connecting key components of the collegiate experience. New Directions for Higher Education, 165, 5162. https://doi.org/:10.1002/he.20083 